The Role of Sleep Disturbance in Predicting Community Response to the Noise of Heavy Weapons

George A. Luz, Edward T. Nykaza,

November 2004

Catherine M.Stewart, and Larry L. Pater
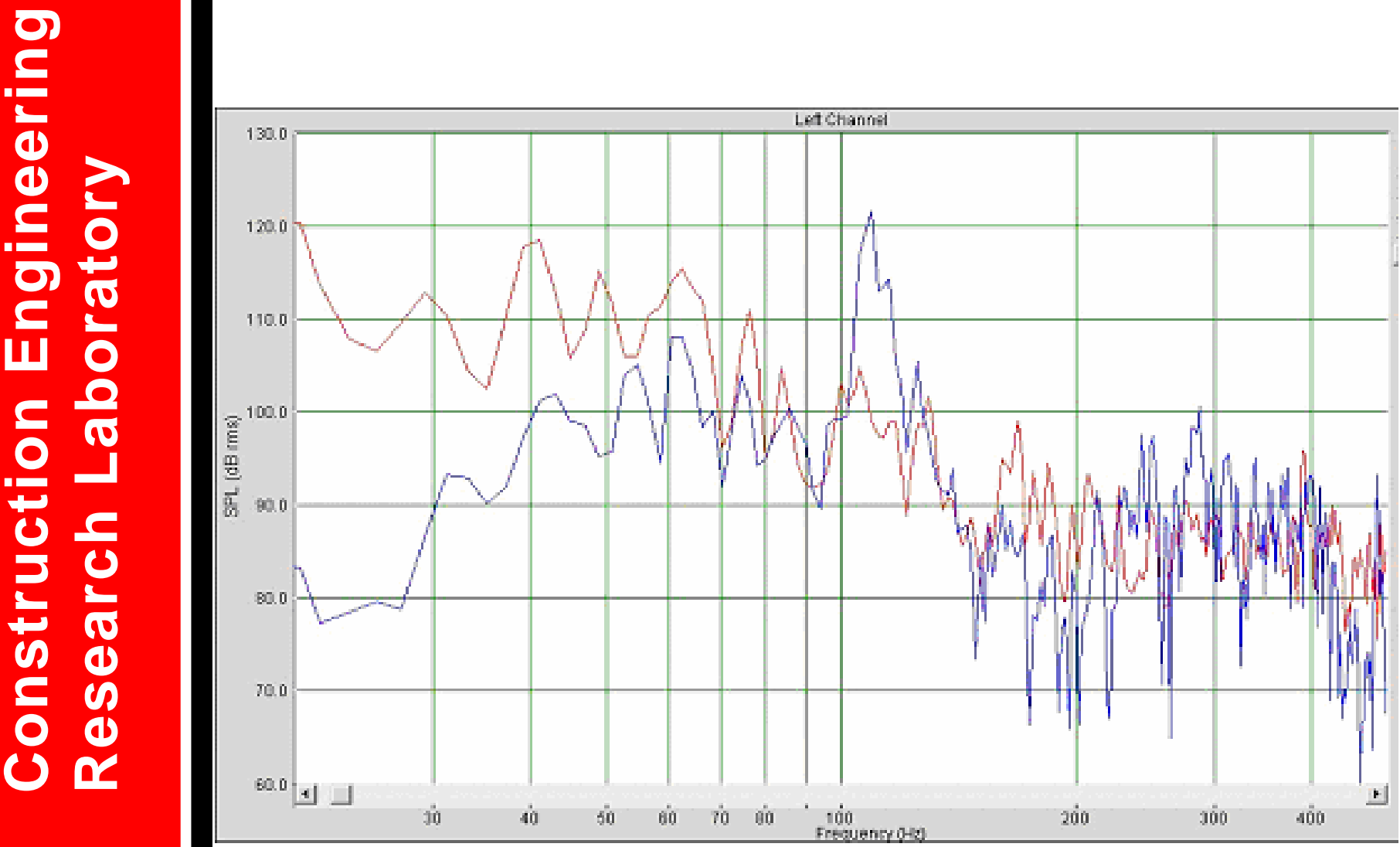



\section{The Role of Sleep Disturbance in Predicting Community Response to the Noise of Heavy Weapons}

George A. Luz and Catherine M. Stewart

U.S. Army Center for Health Promotion and Preventive Medicine 5158 Blackhawk Road

Aberdeen Proving Ground, MD 21010-5402

Edward T. Nykaza and Larry L. Pater

Construction Engineering Research Laboratory

PO Box 9005

Champaign, IL 61826-9005

Final Report

Approved for public release; distribution is unlimited.

Prepared for U.S. Army Corps of Engineers

Washington, DC 20314-1000

and

U.S. Army Center for Health Promotion and Preventive Medicine Aberdeen Proving Ground, MD 21010-5402 
ABSTRACT: One of the most common sources of noise complaints around Army and Marine firing ranges is nighttime gunfire. Testing and training during the hours of darkness is absolutely essential to combat readiness. However, sound travels farther at night, and people are particularly sensitive to noise when they are trying to sleep. Currently, installation commanders are without a procedure to determine whether a particular operation is going to disturb sleep. The purpose of this research is to develop such a procedure.

The primary objective was to establish whether a commercially available instrument for measuring sleep disturbance is suitable for measuring awakening among subjects exposed to the sounds of heavy weapons. The secondary objective was to determine if there is a time when people are less sensitive to noises so that a range operator could reduce annoyance through systematic scheduling of night fire.

In general, the decibel level had an effect on the response. The higher peak decibel level was more likely to wake someone. Day of the study did not affect the response. Time was observed in some analyses to have a slight effect on waking. The feasibility of conducting a sleep disturbance study was established.

DISCLAIMER: The contents of this report are not to be used for advertising, publication, or promotional purposes.

Citation of trade names does not constitute an official endorsement or approval of the use of such commercial products.

All product names and trademarks cited are the property of their respective owners. The findings of this report are not to be construed as an official Department of the Army position unless so designated by other authorized documents.

DESTROY THIS REPORT WHEN IT IS NO LONGER NEEDED. DO NOT RETURN IT TO THE ORIGINATOR. 


\section{Contents}

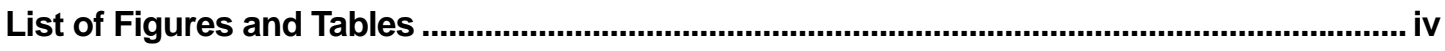

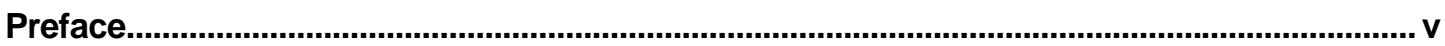

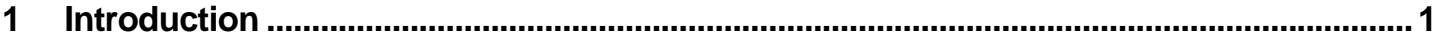

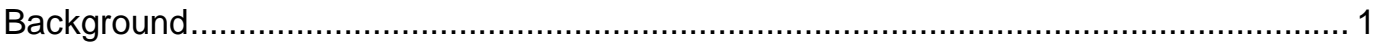

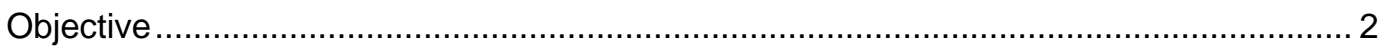

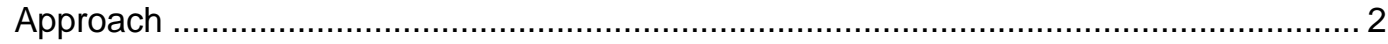

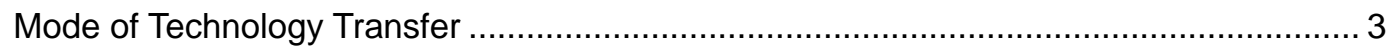

2 Literature Review ........................................................................................................ 4

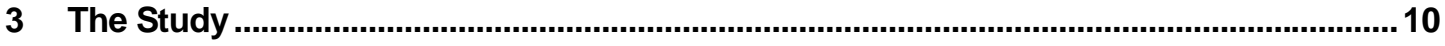

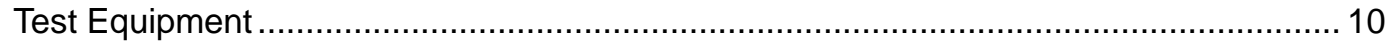

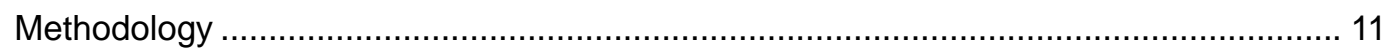

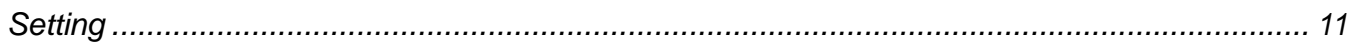

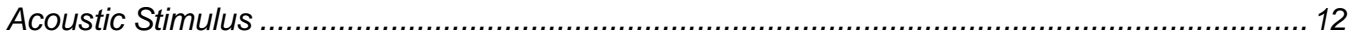

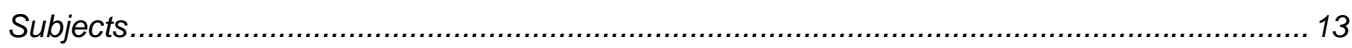

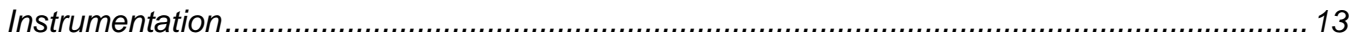

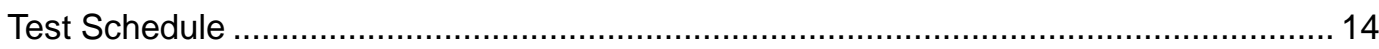

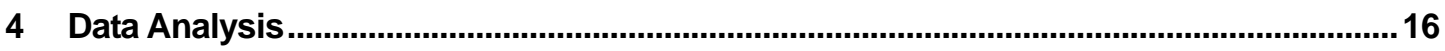

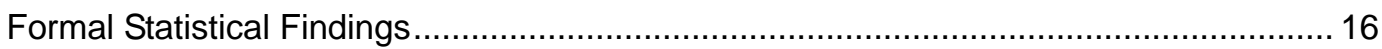

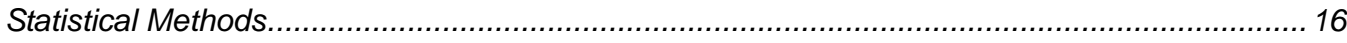

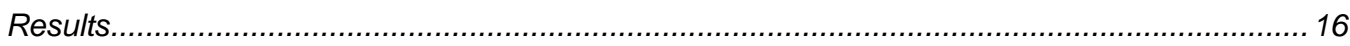

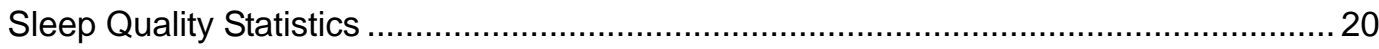

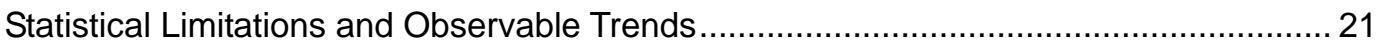

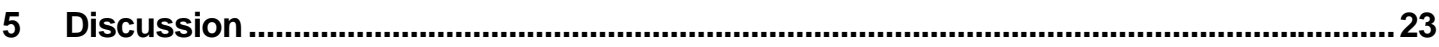

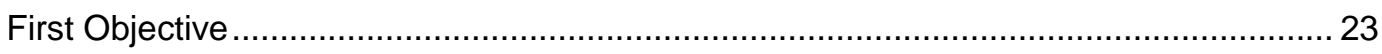

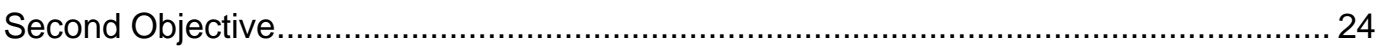

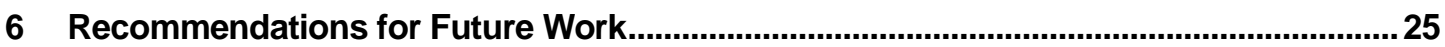

REPORT DOCUMENTATION PAGE ...........................................................................................2 27 


\section{List of Figures and Tables}

\section{Figures}

1. Two of the tents used in the pilot study.

2. Spectrum of original blast (red line) plotted alongside the spectrum of reproduced blast (blue line).

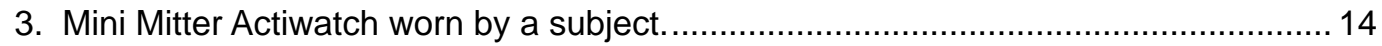

4. Percent of sleep time spent in motion at home and in laboratory.............................. 20

5. Average sleep disturbance for all subjects and all days combined.......................... 21

\section{Tables}

1. Logistic regression analysis, with Awake people excluded, Response: Disturb. ...... 17

2. Logistic regression analysis, with Awake people excluded, Response: Mark.

3. Logistic regression analysis, with Awake people treated as responding, Response: Disturb.

4. Logistic regression analysis, with Awake people treated as responding, Response: Mark.

5. Logistic regression analysis, with Awake people treated as not responding, Response: Disturb.

6. Logistic regression analysis, with Awake people treated as not responding, Response: Mark. 


\section{Preface}

This study was conducted for the Office of the Director of Environmental Programs under A896, "Base Facilities Environmental Quality"; Work Unit number CNN-T352, "Blast Noise Impacts on Sleep." The technical monitor was William Russell, U.S. Army Center for Health Promotion and Preventive Medicine.

The work was performed by the Ecological Processes Branch $(\mathrm{CN}-\mathrm{N})$ of the Installations Division (CN), Construction Engineering Research Laboratory (CERL). The CERL Principal Investigator was Dr. Larry L. Pater. This work was a joint effort done in part by George A. Luz and Catherine M. Stewart, USACHPPM under W81EWF-30077995. The technical editor was Gloria J. Wienke, Information Technology Laboratory. Stephen E. Hodapp is Chief, CEERD-CN-N, and Dr. John T. Bandy is Chief, CEERD-CN. The associated Technical Directors were Gary W. Schanche and Dr. William Severinghaus, CEERD-CV-T. The Director of CERL is Dr. Alan W. Moore.

CERL is an element of the U.S. Army Engineer Research and Development Center (ERDC), U.S. Army Corps of Engineers. The Commander and Executive Director of ERDC is COL James R. Rowan, EN and the Director of ERDC is Dr. James R. Houston. 



\section{Introduction}

\section{Background}

A potential cause of noise complaints around Army and Marine firing ranges is nighttime gunfire. Testing and training during the hours of darkness is absolutely essential to combat readiness. At the same time, sound travels farther at night, and people may be particularly sensitive to noise when they are trying to sleep. In response to actual or potential complaints about nighttime gunfire, a number of installations have introduced nighttime curfews. These curfews require unit commanders to request a waiver from the installation commander if there is a need to train past the curfew hour. Currently, installation commanders are without a procedure to determine whether a particular operation is likely to disturb sleep and result in complaints. The purpose of this research is to develop such a procedure.

Two considerations should be made in determining the impact of blast noise at night: (1) Are people more annoyed at a given sound level when they experience the blast during the evening or during the night? and (2) At what sound level will a blast awaken people? Research conducted around military firing ranges in Sweden leaves open the possibility that evening hours are more critical for determining annoyance than night hours. Rylander and Lundquist ${ }^{1}$ analyzed the annoyance of 399 persons who were living near 8 heavy weapons ranges and had stated that they were "a little," "rather," or "very annoyed" in response to a postal questionnaire. When asked about the time of day when they were most annoyed by the sounds of heavy weapons, about half chose the evening and about a third chose the night. About 10 percent stated that the shooting made it difficult to fall asleep and about the same percentage stated that the shooting resulted in awakening. Because Rylander and Lundquist did not have information on the number of blasts during the evening and night, their data cannot provide a definitive answer about the impact of blast noise at night.

\footnotetext{
1 R. Rylander and B. Lundquist, "Annoyance caused by noise from heavy weapon shooting ranges," J. Sound and Vib. 192, 1996, 199-202.
} 
Research has begun to determine the effect of blast noise on sleep. Definitive results will guide meaningful noise impact assessment protocols, and will ultimately provide decision support to command in scheduling night firing. This report presents the results of the first phase of that research.

\section{Objective}

There were two objectives for the first phase of research. The primary objective was to establish whether a commercially available instrument for measuring sleep disturbance is suitable for measuring awakening among subjects exposed to the sounds of heavy weapons while sleeping. The secondary objective was to determine if there is a time "window" when people are less sensitive to blast noises, as in a German study of sleep disturbance from 120-mm tank gunnery noise. ${ }^{2}$ Achieving these objectives will provide a foundation for the second phase of research, which will study sleep disturbance in communities located near tank or artillery firing ranges.

\section{Approach}

In this experiment, subjects wore a commercially available, wrist-mounted motion detector while sleeping in the Hostile Environment Simulator (HES) chamber operated by the Human Research and Engineering Directorate (HRED) of the Army Research Laboratory (ARL). Subjects were tested in groups of four, over four sequential nights. Each subject slept in the HES chamber on an air mattress inside a single-person tent. On Monday and Tuesday nights, subjects slept without exposure to any electronically reproduced acoustic signal. On Wednesday and Thursday nights, subjects were subjected to an electronically reproduced blast recorded from the firing of a 120-mm tank cannon. To check for changes in sensitivity during the sleeping hours, two blasts were presented at the rate of one pair per hour, beginning at 2300 and ending by 0500 (a total of 12 blasts). One of each pair was at a nominal peak level of 110 decibels (dB) and the other at a nominal peak level of $120 \mathrm{~dB}$. The time of each event was chosen randomly so that in any given hour, the lesser blast had the same probability of

\footnotetext{
2 B. Griefahn, "Effects of military noise during sleep, Relations to sex and time of night," In: B. Berglund et al., (eds) Noise as a Public Health Problem: New Advances in Noise Research (Swedish Council for Building Research, Stockholm, Sweden, 1990).
} 
coming first as did the greater blast. This study used two measures of sleep disturbance. The first was the occurrence of a button push indicating awakening within 15 seconds of the occurrence of a blast. The second was movement during the 15 second period following a blast (without movement during the 30 seconds before the blast.)

\section{Mode of Technology Transfer}

The results of this first phase of research will be used to plan a field study of sleep disturbance among people living close enough to artillery or tank gunnery ranges to be exposed to blast noise at linear peak levels of $115 \mathrm{~dB}$ or greater (measured outdoors) while sleeping in their own beds. ${ }^{3}$ The results of the field study will provide the basis for new recommendations to installations as deemed appropriate by experts at the U.S. Army Engineer Research and Development Center/Construction Engineering Research Laboratory (ERDC/CERL) and at the U.S. Army Center for Health Promotion and Preventive Medicine (USACHPPM).

This report will be made accessible through the World Wide Web (WWW) at URL:

http://www.cecer.army.mil

\footnotetext{
${ }^{3}$ An outdoor peak level of $115-\mathrm{dB}$ is a convenient value for two reasons. First, when awake and in their own homes, people begin to complain when outdoor peak gun blast levels exceed 115-dB (G.A. Luz and K. Eastridge, "An analysis of the performance of an on-line monitoring system for community complaints about gun noise," Proceedings of Noise-Con 2001 (Institute of Noise Control: Poughkeepsie, NY, 2002). Second, automated blast noise monitoring units with thresholds set below a peak level of $115-\mathrm{dB}$ tend to pick up a lot of false alarms.
} 


\section{Literature Review}

For over a quarter century, the U.S. Army has assessed the environmental impact of weapons noise on communities using the $\mathrm{C}$-weighted day-night average sound level (CDNL). This method of assessing community annoyance was first recommended by the National Academy of Sciences-National Research Council Committee on Hearing, Bioacoustics, and Biomechanics (CHABA) in 1977. 4 An important feature of the CDNL is a $10-\mathrm{dB}$ penalty adjustment to events heard between 2200 and 0700 .

CHABA's decision on penalizing nighttime noise by $10 \mathrm{~dB}$ was based more on tradition than scientific data. The tradition came from early work on assessing the annoyance of military airfields ${ }^{5}$, and, for lack of a better number, CHABA retained the $10-\mathrm{dB}$ penalty. In 1977 , the decision to retain the traditional $10-\mathrm{dB}$ night penalty had little consequence for the Army, because the volume of night fire was relatively low. By the 1990's, however, the availability of sophisticated night vision devices mandated a mastery of night firing at every level of Army training. Under the rules of CDNL, each round fired at night between 2200 and 0700 hours adds as much noise to the cumulative "noise dose" as ten rounds fired between 0700 and 2200. In an attempt to establish whether this penalty is too high, researchers analyzed self-reports from people living near a military installation 6 . One conclusion of that early study was that the nighttime penalty might indeed be too high.

Establishing the correct nighttime penalty became even more critical with the American National Standards Institute's (ANSI) publication of a revised proce-

\footnotetext{
4 Report of Working Group 69, Committee on Hearing, Bioacoustics and Biomechanics, Assembly of Behavioral and Social Sciences, Guidelines for Preparing Environmental Impact Statements on Noise (National Research Council, National Academy of Science, 1977).

5 K.N. Stevens and A.C. Pietrasanta, "Procedures for Estimating Noise Exposure and Resulting Community Reactions from Air Base Operations," WADC TN-57-10 (Wright Patterson Air Force Base, Ohio, 1957).

6 P.D. Schomer, “Time of day noise adjustments or 'penalties"' J. Acoust. Soc. Am. 73 (2), 1983, 546-555.
} 
dure for calculating the CDNL. ${ }^{7}$ The revised procedure attempts to account for the fact that the annoyance of an explosion increases at a much higher rate with increasing decibels than does the annoyance of aircraft noise. In the ANSI revision, a 5-dB increase in the sound level of a blast equates to a doubling of perceived annoyance, whereas a 10- $\mathrm{dB}$ increase in the sound level of an aircraft flyover equates to a doubling of perceived annoyance. When applying these assumptions to the mathematical modeling of the annual cumulative exposure near Army training sites, a single high-level event during the night can dominate the calculation, introducing statistical uncertainty.

A study more supportive of the hypothesis that noise during the sleeping hours contributes less to total annoyance than noise during the waking hours was conducted at the Los Angeles International Airport (LAX). In an effort to reduce community annoyance, flights between 2300 and 0600 were eliminated. ${ }^{8}$ In the LAX study, approximately 1400 interviews were conducted before, immediately after, and a month after the cessation of flights. Overall, almost 56 percent of the respondents replied that they had not noticed any change in number of flights; about 20 percent claimed that they noticed fewer flights, and about 20 percent claimed that they noticed more flights. Many of the respondents who claimed that there were fewer flights were in fact aware of the restrictions on night operations. A common comment was, "How could I have noticed? I was asleep." Although the CDNL was reduced, the annoyance stayed the same.

If, as the LAX study suggested, nighttime events that do not lead to awakening do not contribute to annoyance, then a blast occurring at times when people are normally asleep should not be included in the calculation of CDNL. To add a 10$\mathrm{dB}$ penalty to an event that no one notices can only lead to erroneous predictions and defective environmental impact assessments.

There is a fairly large body of literature on sleep disturbance from aircraft noise, but very few studies on sleep disturbance from explosions. An important generalization from the studies of sleep disturbance from non-impulsive noise is the large disparity between thresholds of awakening established in a laboratory and

\footnotetext{
7 Quantities and Procedures for Description and Measurement of Environmental Sound - Part 4: Noise Assessment and Prediction of Long Term Community Response, ANSI S-12.9-1996, Part 4, Approved 6 November 1996.

8 S. Fidell and G. Jones, "Effects of cessation of late night flights on an airport community," J. Sound and Vib. 42, 1975, 411-427.
} 
with subjects at home. ${ }^{9}$ Also, people who live in the vicinity of airports have a higher threshold of awakening from flyovers than those who do not. An experiment by Whitehead and Hume ${ }^{10}$ suggests that the higher sleep disturbance thresholds of people living near airports is due to both the security of sleeping in a familiar environment and being exposed to familiar intrusive sounds. Whitehead and Hume used four measures of sleep disturbance recorded from the brain (EEG), eye muscles (EOG), voluntary muscles (EMG), and heart (ECG) of 21 subjects, aged 22 through 37, sleeping in their own homes. None of these homes were in the vicinity of airports. When the experimenters introduced prerecorded aircraft noise events, average sleep disturbance was intermediate between laboratory and field data for the range of sound levels studied.

All of the published studies on sleep disturbance from impulse noise are laboratory studies, and most used simulated or real sonic booms. Thus, there is every reason to expect that the thresholds of awakening from familiar booms experienced by people sleeping in their own homes would be higher than observed in the laboratory. The only laboratory studies of awakening from tank gunnery are from the German sleep researcher, Barbara Griefahn, who used a high-quality video recorder to capture the sounds of the 120 -mm tank cannon at $1.5 \mathrm{~km}$ behind the firing line. ${ }^{11}$ The time history of Griefahn's shot is comparable to the time histories captured by CHPPM at $1 \mathrm{~km}$ behind $120-\mathrm{mm}$ tank cannons. 12 Unfortunately, Griefahn did not publish the time history or spectrum of the stimulus presented over two loudspeakers and measured at the subject's head. The only descriptions of the reproduced tank shots were maximum A-weighted levels, 78 to $82 \mathrm{dBA}$. Presumably, "maximum A-weighted level" denotes Aweighted fast, because the values of 78 to $82 \mathrm{dBA}$ fall in line with an empirically derived, best fit A-weighted fast equation from Buchta. 13 Buchta's best fit equa-

9 K. Pearsons, D. Barber, B. Tabachnick, "Analyses of the Predictability of Noise-Induced Sleep Disturbance," HSDTR-89-029, Noise and Sonic Boom Impact Technology, Human Systems Division, Air Force Systems Command, Brooks Air Force Base, TX, October 1989.

10 C. Whitehead and K. Hume, "A field experiment of the effect of aircraft noise on sleep," 1989, http://www.sro.org/cftemplate/wfsrcongress/selcits.cfm?SelCuts=19998294

11 B. Griefhan, “Cardiac responses caused by shots of tanks during sleep," J. Sound and Vib., 128, 1989, 109-119.

12 Environmental Noise Study No. 52-69-7080-98, Monitoring of Noise from Tank Gunnery, Camp Shelby, Mississippi, June 1995, August 1996, January 1997, August 1997, U.S Army Center for Health Promotion and Preventive Medicine, Aberdeen Proving Ground, MD 21010-5403, 15 April 1998.

13 Pilotprojekt fuer passive Schallschutzmassnahmen am Truppenuebungsplatz Grafenwoehr [Pilot project for passive noise mitigation at the Grafenwoehr Training Area], German Ministry of Finance, 1988, Figure 5.1.2-6. 
tions for predicting the A-weighted slow, A-weighted fast, and linear peak from the $120 \mathrm{~mm}$ tank shot are as follows:

Peak Level in $\mathrm{dB}=142.2-28 * \log (\mathrm{D} / 250)$

A-fast $=109.5-30.6 * \log (\mathrm{D} / 250)$

A-slow $=103.6-30.4 * \log (\mathrm{D} / 250)$

where $\mathrm{D}$ is in meters

At 1500 meters, Buchta's equations predict a linear peak of 120.4, an A-weighted fast maximum of 85.7, and an A-weighted slow maximum of 79.9. These are predictions of outdoor levels, so Greifahn's indoor measurements of 78 to $82 \mathrm{dBA}$ are consistent with an outdoor-to-indoor attenuation of 4 to $8 \mathrm{dBA}$. This is a reasonable estimate of outdoor-to-indoor attenuation if one assumes that the subjects are sleeping with open windows; Meloni and Rosenheck estimated the outdoor-to-indoor attenuation for artillery blast noise to be about $7 \mathrm{~dB}$ for a Swiss house with open windows. ${ }^{14}$ Using the same set of equations, the best estimate of the linear peak level at the heads of Griefahn's subjects is 111.7 to $115.7 \mathrm{~dB}$.

In Griefahn's study 20 healthy and normal hearing subjects (10 female, 10 male, 20 to 30 years old) slept in the laboratory from 2300 to 0700 during 13 consecutive nights. The first three nights allowed subjects to adapt to the sleep environment. Beginning on the 4th night, 12 subjects were assigned to the "evening" group and 8 to the "morning" group. The evening group received 23 blasts randomly distributed between 2300 and 0200 . The morning group received 23 blasts randomly distributed between 0400 and 0700. For each group, the stimulus set was repeated on the $7^{\text {th }}, 10^{\text {th }}$, and $13^{\text {th }}$ night for a total of 1,840 trials across the total subject pool. About a quarter of these trials resulted in awakenings (as defined by EEG readings) and about 80 percent resulted in movement. 15

\footnotetext{
14 T. Meloni and A. Rosenheck, "Choice of frequency weighting for the evaluation of weapon noise," J. Acous. Soc. Am. 97, 1995, 3636-3641. Figure 3 shows a "windows open" transfer function of about 7-dB for the dominant frequencies in a tank cannon blast.

15 This information comes from Figure 1 in Griefahn's paper, "Effects of military noise during sleep: relations to sex and time of night," In: Proceedings of the $5^{\text {th }}$ International Congress on Noise as a Public Health Problem, 1988, 39-48. Figure 1 shows approximately 480 ten-second epochs as "awake" during the 10-second epoch of the stimulus presentation. In the second panel, movements during the 10 second epoch after the stimulus presentation appear to number about 80 . Presumably, the scale in the second panel is percent.
} 
For operators of heavy weapons ranges, the most important finding in Griefahn's studies was a greater likelihood of awakening between 0400 and 0700 than between 2300 and 0200. She concluded that mitigation to prevent community noise exposure to blast noise was especially critical in the early morning. This conclusion was further reinforced by measures of heart rate. Griefahn found heart rate increased half a second after the shot. The maximum was reached at 3 to $3.5 \mathrm{sec}$ after the shot and averaged 13 beats per minute. The extent of the cardiac responses was significantly larger in the early morning than in the evening.

The older sonic boom studies contain a better description of the stimulus than found in the report from Griefahn. These older studies were conducted inside a special-purpose simulator installed at Stanford Research Institute (SRI). ${ }^{16}$ To approximate the low frequency content of the spectrum of a sonic boom, the SRI researchers built a room within a room. The inner room was built as normal United States wood frame construction of 2-by-4 studs, 16 inches on center, with a wallboard interior. The outer room was much more solidly constructed and hermetically-sealed. One wall of the outer room contained a large rubber diaphragm driven by a cog-and-piston mechanism to mimic the pressure change and duration of a sonic boom. In short, rather than listening to a blast on a speaker system as was the case for Griefahn's subjects (and the subjects in our current study), the subjects in the SRI laboratory were, in effect, "inside the speaker cabinet." When compared with spectral analyses of real sonic booms recorded inside rooms, the simulated booms had most of the acoustic energy at the same 32-hertz $(\mathrm{Hz})$ maximum. Although the lower frequency bands were about $10 \mathrm{~dB}$ low in the simulated booms, these frequencies would have been inaudible even if they were present.

One of the studies conducted by the SRI team confirmed what many parents of young children have experienced - young children are difficult to awaken. 17 Six persons aged 7, 8, 41, 54, 69, and 72 years old were exposed during 16 experimental nights to simulated sonic booms at a peak level of 123.6 to $135.5 \mathrm{~dB}$ as measured outdoors. The two senior citizens awakened to 43.5 percent, the mid-

\footnotetext{
16 J.S. Lukas and K.D. Kryter,"A Preliminary Study of the Awakening and Startle Effects of Simulated Sonic Booms," NASA Report CR-1193, Prepared under Contract no. NAS 1-6193 by Stanford Research Institute, Menlo Park, CA, for Langley Research Center, National Aeronautics and Space Administration, 1968.

17 J.S. Lukas and K.D. Kryter, "Awakening Effects of Simulated Sonic Booms and Subsonic Aircraft Noise on Six Subjects," 7 to 72 years of Age, NASA Contractor Report, NASA CR 1599, May 1970.
} 
dle-aged pair awakened to 7.3 percent, and the children to 2.4 percent of the booms. Although the SRI team did not report the levels at the subjects' beds, those levels can be estimated from another 1972 study of age differences conducted with a clone of the simulator in which the indoor level was $17.7 \mathrm{~dB}$ below the outdoor level.18 Assuming the same relationship would hold for the SRI study, the indoor peak levels for the 7 to 72 year old subjects are estimated to range from 105.9 to $117.8 \mathrm{~dB}$.

The 1972 study also looked at the relationship between awakening and age. In this case, there were 24 male subjects; 8 subjects each were in groups aged 21 to 26, 40 to 45, and 60 to 72. Although the frequency of awakenings from all causes did increase with age, awakenings attributed to sonic boom did not increase with age. In fact, there were very few awakenings to sonic booms across the entire group. The linear peak level inside the bedroom was $110 \mathrm{~dB}$. Although the simulated booms at a peak level of $110 \mathrm{~dB}$ had no effect on the overall patterns of sleep, they did produce measurable changes in heart rate and basal skin resistance. These changes increased with age.

In addition to an increased sensitivity with age, there is a gender-related sensitivity. The SRI team found women to be somewhat more likely to be awakened by sonic booms then men. 19

\footnotetext{
18 W.E. Collins and P.F. Iampietro, "Simulated Sonic Booms and Sleep: Effects of Repeated Booms of 1.0 PSF," FAA-AM-72-35, FAA Civil Aeromedical Institute, Oklahoma City, 1972.

19 J.S. Lukas, "Awakening effects of simulated sonic booms and aircraft noise on men and women, J. Sound \& Vib., 20, 1970, 457-466.
} 


\section{The Study}

\section{Test Equipment}

During the planning stage of this research, it was clear that a field study could not employ complex equipment, such as an electroencephalogram (EEG) and other physiological measures, as were used in the studies reviewed earlier. 20 First, equipment is expensive to purchase. Second, it requires specially-trained technicians to operate. Finally, such equipment is so intrusive that people living near Army ranges would be unlikely to volunteer as subjects.

In field studies of sleep disturbance from aircraft funded by the U.S. Air Force, researchers employed wrist-worn motion detectors. 21 As a part of the primary objective, this study looked to establish whether such motion detectors would be effective for large weapons noise as well. Effectiveness was judged on the following criteria:

- The instrument had to be reliable.

- The instrument had to be user-friendly.

- The measures had to be sensitive enough to demonstrate a change in response for different blast noise levels (as had been demonstrated with EEG and other physiological measures).

Prior to beginning this study, ERDC/CERL purchased equipment from two competitors of the Mini Mitter Co., Inc. ${ }^{22}$ In one case the instrument had a systematic 8-second timing error, which was inconsequential to its normal use in sleep

\footnotetext{
20 S. Fidell et al., "Field Studies of Habituation to Change in Nighttime Aircraft Noise and of Sleep Motility Measurement Methods," Contract NO. F41624-96-C-9003, prepared for U.S. Air Force, AL/OEBN, Wright Patterson AFB, by BBN Technologies, 13 March 1998.

21 S. Fidell et al., "Field Studies of Habituation to Change in Nighttime Aircraft Noise and of Sleep Motility Measurement Methods," Contract NO. F41624-96-C-9003, prepared for U.S. Air Force, AL/OEBN, Wright Patterson AFB, by BBN Technologies, 13 March 1998.

22 Citation of trade names or manufacturers does not constitute an official endorsement or approval of the use of such commercial products. The findings of this report are not to be construed as an official Department of the Army position, unless so designated by other authorized documents.
} 
research but unacceptable for the precise timing needed to track response to a 200-millisecond blast. In the other case, the company was unable to complete the promised "firmware" in time for the study.

\section{Methodology}

\section{Setting}

Subjects were tested in the Hostile Environment Simulator (HES) chamber operated by the Human Research and Engineering Directorate (HRED) of the Army Research Laboratory (ARL) at Aberdeen Proving Ground, Maryland. The HES room dimensions are: $17.5 \mathrm{~m}$ long by $13.5 \mathrm{~m}$ wide by $6.7 \mathrm{~m}$ high. The walls and ceiling are Industrial Acoustics Company (IAC) chamber walls. The room is equipped with a multi-speaker, high fidelity system capable of reproducing gun shots at peak levels up to 135-dB. Subjects slept on air mattresses in single person tents as shown in Figure 1.

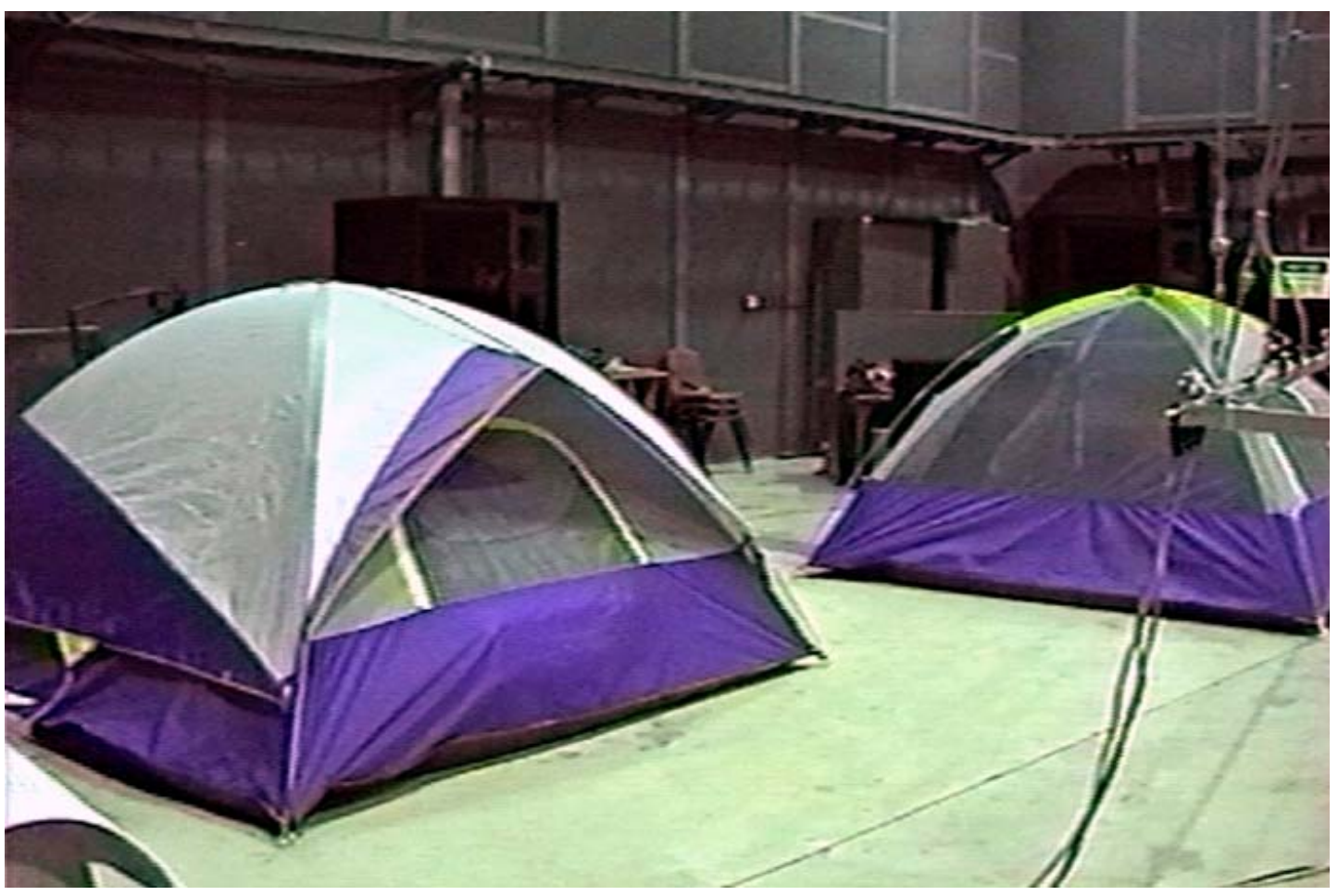

Figure 1. Two of the tents used in the pilot study.

The HES chamber is windowless. Lights were turned off at 2200 and turned on again at 0600 hours. Temperature was kept at $70^{\circ}$ F. Subjects entered and exited the HES chamber through an equipment control room. This control room 
was lighted, and the door was kept slightly ajar to provide dim light for subjects using the restrooms that were located outside the building.

\section{Acoustic Stimulus}

The acoustic stimulus was reproduced from a digital recording made in August 1997 at Camp Shelby, MS, at a distance of about 1 kilometer directly behind a 120-mm tank gun. 23 The original impulse peak level was about $125 \mathrm{~dB}$. In the HES, the blast was filtered to achieve an "indoor sound" as described by Meloni and Rosenheck. 24 This "indoor blast" was reproduced at two peak levels: $120 \mathrm{~dB}$ and $110 \mathrm{~dB}$. These are nominal levels, because the room acoustics did not provide for the exact same level at all four tents. Actual levels were measured using Larson-Davis Laboratories Integrating Sound Level Analyzers (model 870) with condenser microphones (model 2541) and preamplifiers (model 900B). Subjects had a sound analyzer within 1 meter of their heads. Actual peak levels averaged $120.3 \mathrm{~dB}$ (standard deviation $=1.9)$ and $109.0 \mathrm{~dB}($ standard deviation $=2.2)$.

Although the amplifier in the HES was powerful (50,000 watts) and the woofers were high quality, ordinary speakers cannot reproduce low frequencies with enough acoustic power to mimic the blast of a large gun. Figure 2 shows a comparison of the spectra of the original and the reproduced tank blast. Compared to the original, the spectrum of the reproduced blast peaks around $100 \mathrm{~Hz}$ and then drops off at lower frequencies. It should be noted that the loss of the lowest frequencies in the reproduced tank blast did not degrade realism, since these low frequencies are not intense enough to be heard in a $125-\mathrm{dB}$ peak level blast. The reproduced blasts were subjectively judged to sound like the real blasts that occasionally penetrated into the HES chamber from daytime firing at Aberdeen Proving Ground. MD.

With the amplifier gain set to reproduce such an intense acoustic signal, the noise floor of the system was also audible. To eliminate this background noise, the blast signal was digitally gated.

\footnotetext{
23 Environmental Noise Study No. 52-69-7080-98, Monitoring of Noise from Tank Gunnery, Camp Shelby, Mississippi, June 1995, August 1996, January 1997, August 1997, Appendix E, U.S. Army Center for Health Promotion and Preventive Medicine, 15 April 1998.

24 T. Meloni and A. Rosenheck, "Choice of frequency weighting for the evaluation of weapon noise," J. Acoust. Soc. Amer. 97, 1995, 3636-3641.
} 


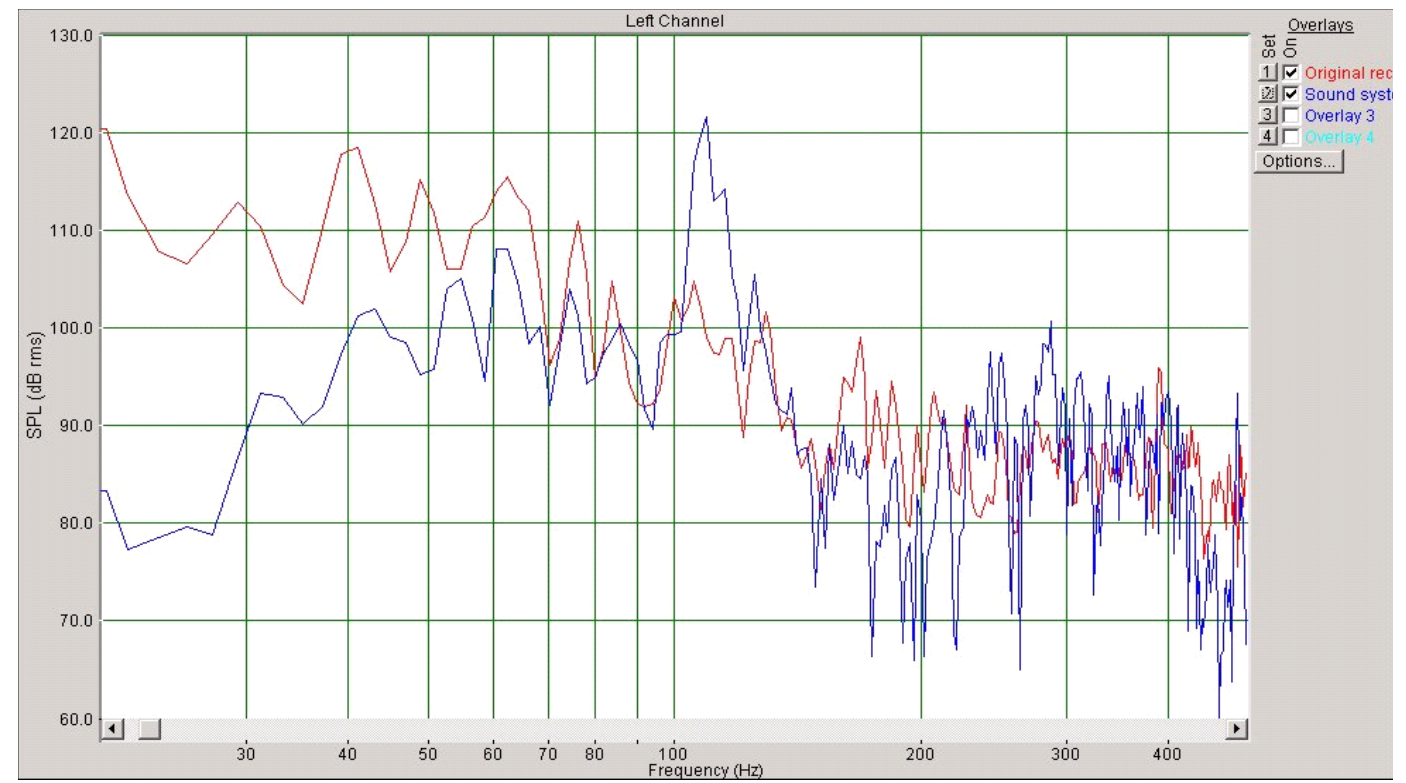

Figure 2. Spectrum of original blast (red line) plotted alongside the spectrum of reproduced blast (blue line).

\section{Subjects}

Eighteen paid subjects (ten women and eight men) were drawn from the Center for Health Promotion and Preventive Medicine work force. Payment was in the form of overtime for the nights during which they slept in the HES chamber. Subject ages ranged between 30 and 60 years old. As directed by the Human Use Review Committee for the Human Research and Engineering Directorate of the Army Research Laboratory, all subjects received audiograms before and after noise exposure. No subjects were screened out on the basis of their audiograms. None suffered from a sleep disorder, and none were taking sleep medication or imbibing alcohol within the hour prior to the initiation of the 2200 "lights out" curfew.

\section{Instrumentation}

Sleep disturbance was measured with the Actiwatch manufactured by the Mini Mitter Co., Inc. As recommended by the manufacturer, the Actiwatch was worn on the nondominant hand. When the hand moves, the accelerometer registers the amount of movement and integrates the accelerometer count over a fixed number of seconds. Because Griefahn's study had shown maximum heart rate acceleration at 3 to $3.5 \mathrm{sec}$, the shortest period available on the Actiwatch was chosen. This period is $15 \mathrm{sec}$, and the default sensitivity settings recommended by the manufacturer were used. In addition to registering movement, the Acti- 
watch has a marker button. The Actiwatch registers the period during which the button was pushed but does not register the exact time it was pushed. Nevertheless, this marker button provided a simple way for subjects to report whether they were awakened by a blast. Figure 3 shows the Actiwatch as worn by one of the subjects.

At the end of each night of sleeping in the HES chamber, data from each Actiwatch was downloaded to Mini Mitter Corporation's proprietary software. This software provides a number of important statistics for evaluating the quality of sleep.

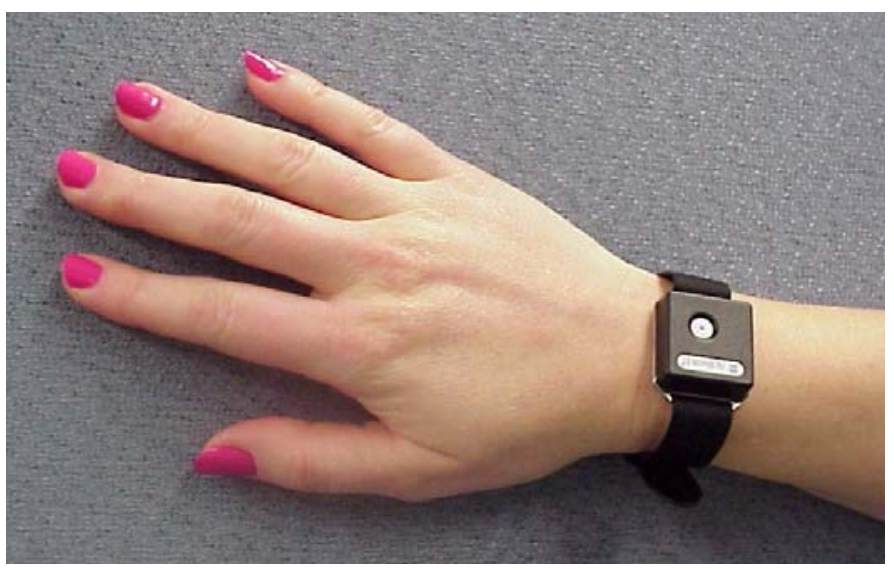

Figure 3. Mini Mitter Actiwatch worn by a subject.

The marker button is visible as a small metal disk.

\section{Test Schedule}

Subjects were run in groups of four. Testing was conducted on four consecutive nights, beginning on Monday night of a normal work week. Subjects were asked to arrive between 2100 and 2130 hours with their own linens and personal items. There were no reading lights in the tents, but subjects who were not sleepy at 2200 hours were given the option to go into an adjoining room and read.

The first group of four males was run without the "house filter" on the reproduced blast. Included in this initial group was the first author, who agreed with the other subjects that the unfiltered blast was too sharp and alerting. The 
awakening data from this initial group was discarded, 25 although one member of the group was later tested with the filtered signal.

Monday and Tuesday nights were periods of acclimatization. Subjects wore the Actiwatch but there were no blasts. Blasts occurred on Wednesday and Thursday night. To study changes in sensitivity during the hours of sleep, two blasts were presented each hour, beginning at 2300 and ending by 0500 hours (a total of 12 blasts per night). During each hour, one of the blasts was a nominal peak level of $110 \mathrm{~dB}$ and the other was a nominal peak level of $120 \mathrm{~dB}$. The time of each blast was chosen randomly so that in any given hour, the lesser blast had the same probability of coming first as did the greater blast.

Subjects were asked to push the event marker on the Actiwatch whenever they heard a blast. To avoid confusion, subjects were asked to distinguish between blasts heard while they were awake and blasts that had awakened them. If they were awake when they heard the blast, they were asked to count to 30 after the first button push and then push the marker button a second time. When analyzing the data, the technician counted a subject as awake if there was a marker in the two sequential 15-second epochs following the blast. Subjects were also asked to fill out a data sheet stating when they thought they had fallen asleep and when they awoke in the morning. The technician operating the Mini Mitter software used this information as part of the quality assurance of the data.

\footnotetext{
25 These data were, however, used in the analyses reported in the next chapter. That analysis focused on the mechanics of the statistics available from the Mini Mitter Co., Inc., and the fact that some of the blasts were different had no bearing on the analysis.
} 


\section{Data Analysis}

\section{Formal Statistical Findings}

\section{Statistical Methods}

A logistic regression was used to determine the likelihood of waking, measured either as a mark or disturb response, comparing (1) the two decibel levels of the noise generated, $110 \mathrm{~dB}$ verses $120 \mathrm{~dB}$, (2) the day on which the study was conducted, Wednesday or Thursday, (3) and the time of the evening, ranging from 2300 to 0500. Types of waking, mark or disturb, were analyzed separately. Hourly intervals, 2400 to 0100,0100 to 0200 , etc. were coded as 1, 2, etc. for ease of analysis. Some people were awake during a time period; therefore, the analysis was performed in three ways: (1) Awake time was eliminated from the analysis, (2) Awake time was treated as no response, and (3) Awake time was treated as a response. Statistical significance was defined as $\mathrm{p}<0.05$.

\section{Results}

Regardless of the analysis of Awake time, similar results were observed for each type of response. In general, the decibel level had an effect on the response. The higher peak decibel level, $120 \mathrm{~dB}$, was approximately 1.4 to 1.5 times more likely to wake someone than the 110-dB noise level (Refer to Column $\operatorname{Exp}(\mathrm{B})$ in Tables 1-6). This was significant at the $\mathrm{p}<0.10$ level. Day of the study did not affect the response. However, time was observed in some analyses to have a slight effect on waking. It appeared that people at later times were less likely to respond than at the earliest time, 2300 to 2400 .

Tables 1 through 6 display the output from the three logistic regressions for each type of response, Mark or Disturb. 
Table 1. Logistic regression analysis, with Awake people excluded, Response: Disturb.

Variables in the Equation

\begin{tabular}{|c|c|c|c|c|c|c|c|}
\hline & $B$ & S.E. & Wald & $\mathrm{df}$ & Sig. & $\operatorname{Exp}(B)$ \\
\hline \multirow{9}{*}{$\begin{array}{l}\text { Step } \\
1\end{array}$} & $\overline{\mathrm{DAY}(1)}$ & -.258 & .230 & 1.256 & 1 & .262 & .773 \\
\hline & DECIBEL(1) & .384 & .230 & 2.787 & 1 & .095 & 1.468 \\
\hline & TIME & & & 9.414 & 5 & .094 & \\
\hline & TIME(1) & -.817 & .407 & 4.038 & 1 & .044 & .442 \\
\hline & TIME(2) & -.984 & .412 & 5.696 & 1 & .017 & .374 \\
\hline & TIME(3) & -.635 & .407 & 2.430 & 1 & .119 & .530 \\
\hline & TIME(4) & -1.188 & .419 & 8.048 & 1 & .005 & .305 \\
\hline & TIME(5) & -.663 & .409 & 2.624 & 1 & .105 & .515 \\
\hline & Constant & .531 & .354 & 2.254 & 1 & .133 & 1.701 \\
\hline
\end{tabular}

a. Variable(s) entered on step 1: DAY, DECIBEL, TIME.

b. TYPE = disturb

Table 2. Logistic regression analysis, with Awake people excluded, Response: Mark.

Variables in the Equatior?

\begin{tabular}{|c|c|c|c|c|c|c|c|}
\hline & $B$ & S.E. & Wald & $\mathrm{df}$ & Sig. & $\operatorname{Exp}(B)$ \\
\hline \multirow{9}{*}{$\begin{array}{l}\text { Step } \\
1\end{array}$} & $\overline{\mathrm{DAY}(1)}$ & .208 & .242 & .743 & 1 & .389 & 1.232 \\
\hline & DECIBEL(1) & .421 & .243 & 3.011 & 1 & .083 & 1.524 \\
\hline & TIME & & & 5.945 & 5 & .312 & \\
\hline & TIME(1) & -.659 & .409 & 2.595 & 1 & .107 & .517 \\
\hline & TIME(2) & -.867 & .422 & 4.222 & 1 & .040 & .420 \\
\hline & TIME(3) & -.464 & .405 & 1.312 & 1 & .252 & .629 \\
\hline & TIME(4) & -.839 & .423 & 3.941 & 1 & .047 & .432 \\
\hline & TIME(5) & -.687 & .414 & 2.753 & 1 & .097 & .503 \\
\hline & Constant & -.435 & .351 & 1.534 & 1 & .216 & .647 \\
\hline
\end{tabular}

a. Variable(s) entered on step 1: DAY, DECIBEL, TIME.

b. TYPE = mark 
Table 3. Logistic regression analysis, with Awake people treated as responding, Response: Disturb.

Variables in the Equation

\begin{tabular}{|c|c|c|c|c|c|c|c|}
\hline & & B & S.E. & Wald & df & Sig. & $\operatorname{Exp}(B)$ \\
\hline \multirow{9}{*}{$\begin{array}{l}\text { Step } \\
1 \\
1\end{array}$} & DAY(1) & -.218 & .225 & .937 & 1 & .333 & .804 \\
\hline & DECIBEL(1) & .388 & .225 & 2.964 & 1 & .085 & 1.474 \\
\hline & TIME & & & 12.510 & 5 & .028 & \\
\hline & TIME(1) & -1.059 & .398 & 7.058 & 1 & .008 & .347 \\
\hline & TIME(2) & -1.132 & .399 & 8.038 & 1 & .005 & .322 \\
\hline & TIME(3) & -.841 & .397 & 4.477 & 1 & .034 & .431 \\
\hline & TIME(4) & -1.282 & .402 & 10.173 & 1 & .001 & .278 \\
\hline & TIME(5) & -.841 & .397 & 4.477 & 1 & .034 & .431 \\
\hline & Constant & .750 & .340 & 4.857 & 1 & .028 & 2.116 \\
\hline
\end{tabular}

a. Variable(s) entered on step 1: DAY, DECIBEL, TIME.

b. TYPE = disturb

Table 4. Logistic regression analysis, with Awake people treated as responding, Response: Mark.

Variables in the Equation

\begin{tabular}{|c|c|c|c|c|c|c|c|}
\hline & $\mathrm{B}$ & S.E. & Wald & df & Sig. & $\operatorname{Exp}(B)$ \\
\hline \multirow{9}{*}{$\begin{array}{l}\text { Step } \\
1 \\
1\end{array}$} & $\overline{\mathrm{DAY}(1)}$ & .224 & .233 & .927 & 1 & .336 & 1.252 \\
\hline & DECIBEL(1) & .423 & .234 & 3.275 & 1 & .070 & 1.527 \\
\hline & TIME & & & 10.256 & 5 & .068 & \\
\hline & TIME(1) & -.975 & .395 & 6.083 & 1 & .014 & .377 \\
\hline & TIME(2) & -1.059 & .398 & 7.059 & 1 & .008 & .347 \\
\hline & TIME(3) & -.735 & .388 & 3.595 & 1 & .058 & .479 \\
\hline & TIME(4) & -.975 & .395 & 6.083 & 1 & .014 & .377 \\
\hline & TIME(5) & -.893 & .392 & 5.180 & 1 & .023 & .409 \\
\hline & Constant & -.129 & .326 & .157 & 1 & .692 & .879 \\
\hline
\end{tabular}

a. Variable(s) entered on step 1: DAY, DECIBEL, TIME.

b. TYPE = mark 
Table 5. Logistic regression analysis, with Awake people treated as not responding, Response: Disturb.

Variables in the Equation

\begin{tabular}{|c|c|c|c|c|c|c|c|}
\hline & & B & S.E. & Wald & df & Sig. & $\operatorname{Exp}(B)$ \\
\hline \multirow{9}{*}{$\begin{array}{l}\text { Step } \\
1 \\
1\end{array}$} & DAY(1) & -.239 & .224 & 1.136 & 1 & .286 & .788 \\
\hline & DECIBEL(1) & .362 & .224 & 2.597 & 1 & .107 & 1.436 \\
\hline & TIME & & & 6.195 & 5 & .288 & \\
\hline & TIME(1) & -.436 & .383 & 1.296 & 1 & .255 & .647 \\
\hline & TIME(2) & -.658 & .386 & 2.910 & 1 & .088 & .518 \\
\hline & TIME(3) & -.290 & .382 & .578 & 1 & .447 & .748 \\
\hline & TIME(4) & -.892 & .392 & 5.174 & 1 & .023 & .410 \\
\hline & TIME(5) & -.363 & .382 & .902 & 1 & .342 & .696 \\
\hline & Constant & .152 & .322 & .222 & 1 & .637 & 1.164 \\
\hline
\end{tabular}

a. Variable(s) entered on step 1: DAY, DECIBEL, TIME.

b. TYPE = disturb

Table 6. Logistic regression analysis, with Awake people treated as not responding, Response: Mark.

Variables in the Equation

\begin{tabular}{|c|c|c|c|c|c|c|c|}
\hline & $B$ & S.E. & Wald & $\mathrm{df}$ & Sig. & $\operatorname{Exp}(B)$ \\
\hline \multirow{9}{*}{$\begin{array}{l}\text { Step } \\
1\end{array}$} & $\overline{\mathrm{DAY}(1)}$ & .209 & .238 & .766 & 1 & .381 & 1.232 \\
\hline & DECIBEL(1) & .417 & .240 & 3.033 & 1 & .082 & 1.518 \\
\hline & TIME & & & 3.931 & 5 & .559 & \\
\hline & TIME(1) & -.391 & .397 & .969 & 1 & .325 & .677 \\
\hline & TIME(2) & -.652 & .408 & 2.548 & 1 & .110 & .521 \\
\hline & TIME(3) & -.229 & .392 & .343 & 1 & .558 & .795 \\
\hline & TIME(4) & -.652 & .408 & 2.548 & 1 & .110 & .521 \\
\hline & TIME(5) & -.475 & .400 & 1.408 & 1 & .235 & .622 \\
\hline & Constant & -.701 & .335 & 4.386 & 1 & .036 & .496 \\
\hline
\end{tabular}

a. Variable(s) entered on step 1: DAY, DECIBEL, TIME.

b. TYPE = mark 


\section{Sleep Quality Statistics}

An assumption in planning this study was that sleep quality would be degraded by merely sleeping in a strange environment, as observed by Fidell. ${ }^{26}$ To test for this, some of the subjects wore the Actiwatch while sleeping in their own beds so that sleep quality could be compared between home and lab. The descriptive statistics of sleep quality were part of the standard analysis software available from the Mini Mitter Co., Inc. Some of these statistics, such as when the subjects fell asleep and when they awoke, were not useful in this particular study because the experimental design forced people into a uniform sleep schedule.

A more useful statistic was the percent of sleep spent in motion. As shown in Figure 4, subjects sleeping at home spent a little more than 5 percent of the time in motion. Sleeping in the HES chamber during nights 1 thru 4, percent motion was between 7 and 8 . This measure seemed to be insensitive to the presence or absence of blasts.

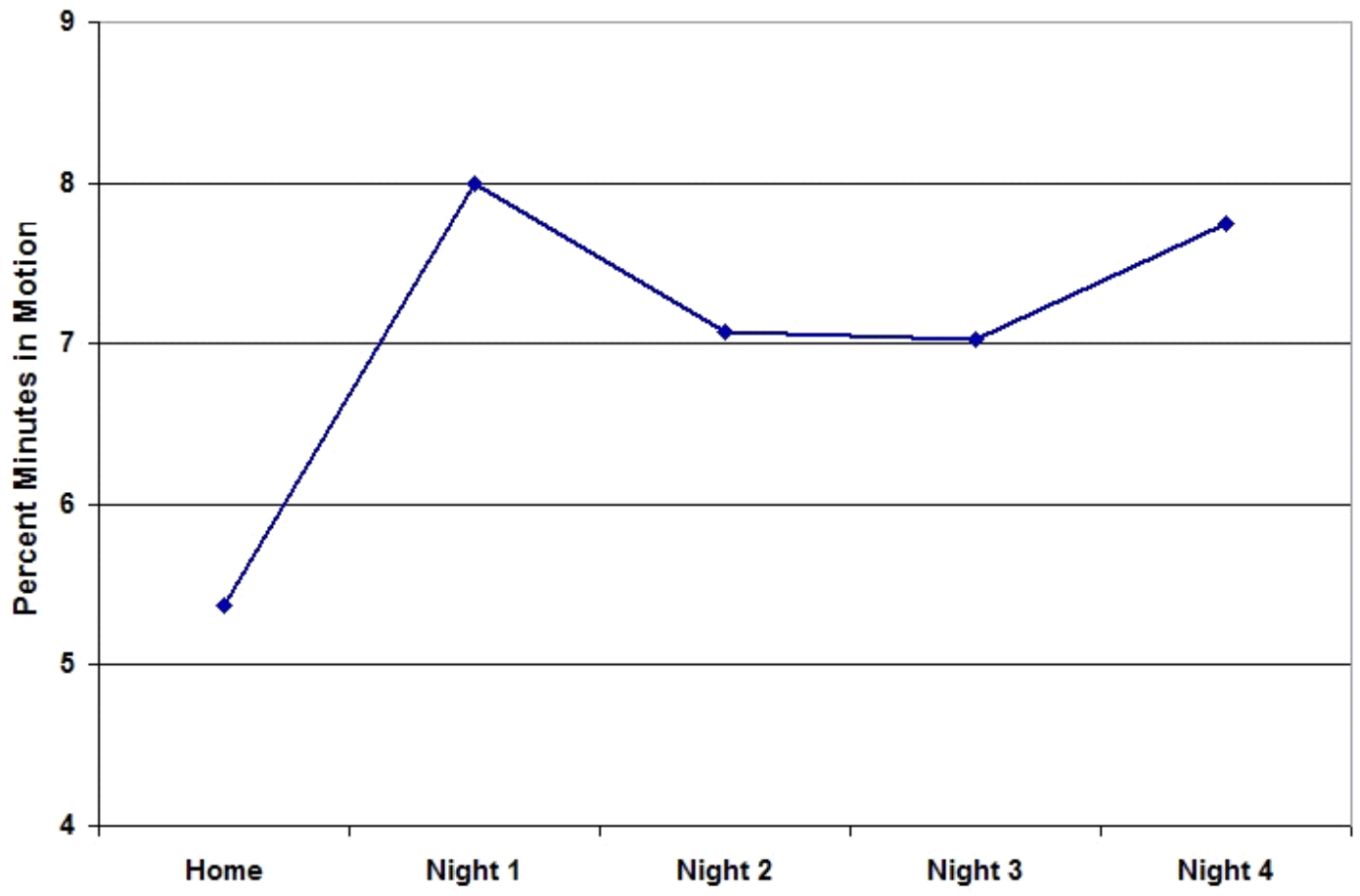

Figure 4. Percent of sleep time spent in motion at home and in laboratory.

\footnotetext{
26 S. Fidell, K. Pearsons, B. Tabachnick, R. Howe, L. Silvati, \& D. S. Barber, "Field study of noise-induced sleep disturbance" J. Acoust. Soc. Am. 98 (2), 1995, 1025-1033.
} 
A measure that appeared to offer some potential for differentiating between sleep with blasts and sleep without blasts was the average length of sleep bouts. For the group (including subjects from the initial group exposed to the unfiltered blast), the average sleep bout was 15 minutes, 24 seconds on nights without blasts and 12 minutes, 48 seconds on nights with blasts. Although this difference was still not statistically significant (Student's T: $p<.09$ with one-tail test), there were only 12 blasts per night. During an actual field study, when the nighttime exposure might be as much as 200 blasts, the average length of sleep bouts could be a very useful statistic.

Average length of wake bouts was too short to differentiate between control and blast exposures. This statistic was $1 \mathrm{~min}, 6 \mathrm{sec}$ on Night 1, $1 \mathrm{~min}$ on Night 2, 54 sec on Night 3 and $48 \mathrm{sec}$ on Night 4. The steady drop is suggestive of a gradual acclimatization to sleeping in the HES chamber, but the differences were too small to be statistically significant.

\section{Statistical Limitations and Observable Trends}

Because the data from the initial group exposed to the unfiltered blast were discarded, data were available from only fifteen subjects. Although there were not enough data to test a complex model of sleep disturbance, the observable trends indicate that a complex model is appropriate. These observable trends can be seen in Figure 5.

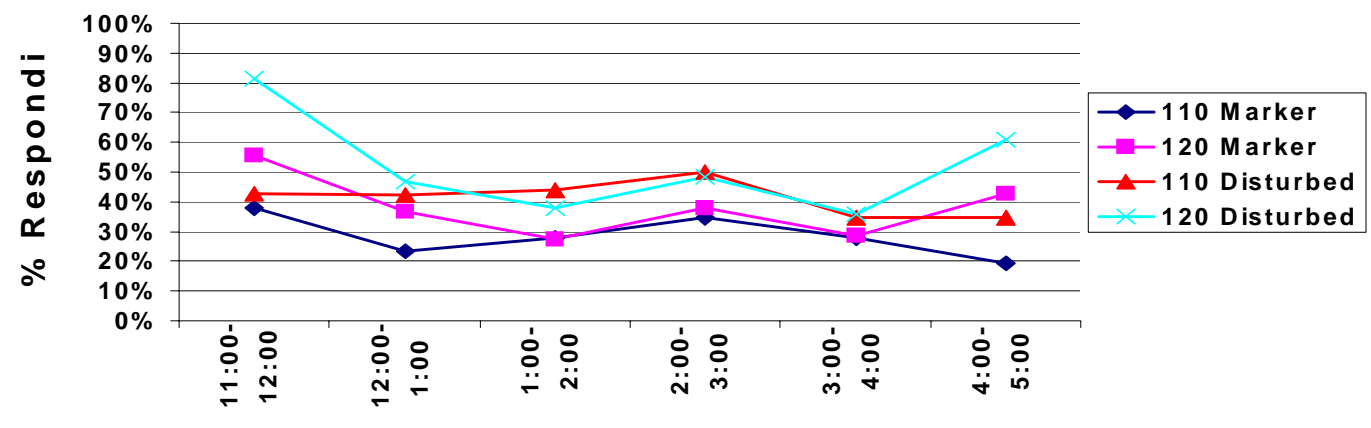

Tim e

Figure 5. Average sleep disturbance for all subjects and all days combined.

Trend 1. Movement (labeled Disturbed in Figure 5) was a more sensitive measure than awakening (labeled Marker in Figure 5). In other words, there were times when people moved in response to the blast but did not awaken. This is 
not a profound finding, but had it not been observed, the reliability of the equipment would be questionable.

Trend 2. In the middle of the night from 2400 to 0400 hours, people tended to be in deepest sleep and decibel differences between the stimulus was not as an important variable in awakening.

Trend 3. During what some sleep researchers call the "shoulder hours," decibel differences were an important variable in awakening. "Shoulder hours" refers to the period during which we are falling to sleep and the period prior to awakening.

Trend 4. In the middle of the night, 50 percent of the subjects showed no response to a peak level blast measuring $120 \mathrm{~dB}$ near their heads, even though these subjects were sleeping under less than ideal conditions. 


\section{Discussion}

As stated earlier, there were two objectives. The primary objective was to establish whether a commercially available instrument for measuring sleep disturbance is suitable for measuring awakening among subjects exposed to the sounds of heavy weapons while sleeping. The secondary objective was to determine if there is a time "window" when people are less sensitive to blast noises, as observed in Griefahn's sleep disturbance study. The primary objective established the feasibility of conducting a sleep disturbance study among citizens living close to a tank or artillery range. The secondary objective established whether a range operator could reduce community annoyance through systematic scheduling of night fire. The primary objective was met and the secondary objective was observed.

\section{First Objective}

It should be noted that, The Mini Mitter Co., Inc. Actiwatch met the stated criteria. Specifically,

\section{- The instrument had to be reliable.}

FINDING: The Actiwatch proved to be fairly reliable. Only 5 percent of the nights of data were lost. Fortunately for the current study, these losses were all on control nights. Also, anecdotal evidence suggests that the marker button seemed to be well-placed and large enough for subjects to push.

- The instrument had to be user friendly.

FINDING: The equipment and software was reasonably user friendly. In this case, the equipment and software was operated by a technician having broad experience operating acoustical and chemical analytical instrumentation.

- The measures had to be sensitive enough to demonstrate a change in response for different blast noise levels (as had been demonstrated with EEG and other physiological measures). 
FINDING: The Actiwatch was operated with the sensitivity setting recommended by the manufacturer. As stated in the statistical section, the $120-\mathrm{dB}$ blasts were approximately 1.4 to 1.5 times more likely to wake someone than the 110-dB noise level. Also, subjects seemed to be more sensitive to differences in level during the shoulder hours than during the deepest part of sleep. 27

\section{Second Objective}

Griefahn found subjects were more likely to be awakened by a recorded tank blast between 0400 and 0700 then between 2300 and 0200 . Observation of the current data shows subjects to be least likely to be awakened by a blast between midnight and 0400. This suggests that people in deep sleep are more tolerant of blasts and that systematic scheduling of nighttime gunfire could reduce the impact of blast noise on the residents of the communities surrounding military installations.

27 An anecdotal observation made by Karl Pearsons during an Air Force-funded study of sleep disturbance from jet aircraft suggests that signal strength may be irrelevant in determining whether or not a deeply-sleeping person will awaken. A subject who rarely awakened to jet aircraft noise awoke to an over flight which was not any louder than the events which had failed to awake him. When asked about the awakening, the subject reported that the planes usually flew from west to east but this plane had flown from east to west. 


\section{Recommendations for Future Work}

A field study should have three essential elements that cannot be duplicated in a laboratory:

1. Subjects should be in their own beds, so their threshold of awakening will be higher. The higher threshold will provide a better prediction of the outcome of a particular explosive operation than can be obtained in the laboratory. Also, the establishment of a higher threshold could lead to a higher "rejection threshold" in the BNOISE2 computer program used to generate noise contour maps.

2. All of the low frequency in a blast should be in the exposure. The reproduced blast lacked a lot of energy below $100 \mathrm{~Hz}$. As argued earlier, the energy below $100 \mathrm{~Hz}$ is not very audible. On the other hand, the energy below $100 \mathrm{~Hz}$ is responsible for house vibration, which may increase the likelihood of awakening.

3. The spacing between multiple blasts should be realistic. In the current study, there were only two blasts per hour and the temporal spacing was too long to allow for an interaction between the first arousal and a second event. In other words, if the first blast doesn't awaken a person, will a second blast heard a few seconds later increase the likelihood of awakening?

The product of the field research should be a set of curves showing the likelihood of arousing a sleeper as a function of noise event level. The intended customers for this product are garrison commanders and their range control officers. Consider, for example, the following paragraph from Fort Benning's USAIC Regulation, Number 210-4, Range and Terrain Regulation (August 1994):

"firing may be conducted at all hours of the day/night if necessary. However, to reduce the noise impact ... efforts should be taken to terminate firing of all weapons except small arms between 2400-0600, if possible.

Having achieved the first two objectives, a field study can be expected to be successful, yielding data useful to the Army's environmental noise management ef-

fort. Locations where people are living close enough to tank gunnery ranges to be disturbed by night firing include: 
- Natural Bridge and Antwerp, NY (Fort Drum)

- Lebanon Junction, Kentucky (Fort Knox)

- La Fayette, Kentucky (Fort Campbell)

- Lockwood, California (Fort Hunter Liggett)

- Bala, Kansas (Fort Riley)

- Outskirts of Brooklyn Mississippi (Camp Shelby)

- Hastings Range (Fort Benning)

Planning a field study will, however, be more difficult than conducting a laboratory study. First, approval from the commander of the installation operating the ranges is absolutely essential. Second, with the extended deployment of combat units, the amount of armor training in the continental United States has been markedly reduced. For example, the commander of Fort Hunter Liggett approved the conducting of the field study in June 2003. However, the study had to be cancelled when the California Army National Guard cancelled their training. 


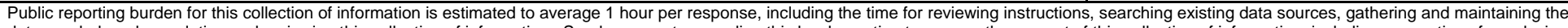

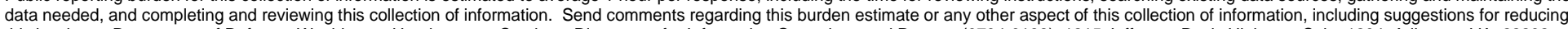

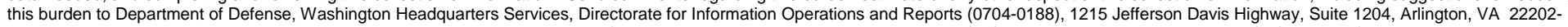

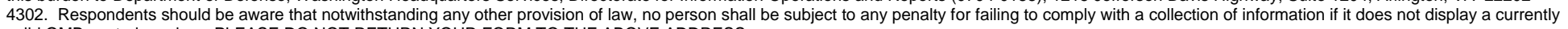
valid OMB control number. PLEASE DO NOT RETURN YOUR FORM TO THE ABOVE ADDRESS.
1. REPORT DATE (DD-MM-YYYY)
2. REPORT TYPE
3. DATES COVERED (From - To)

$11-2004$

Final

4. TITLE AND SUBTITLE

The Role of Sleep Disturbance in Predicting Community Response to the Noise of Heavy

Weapons

5a. CONTRACT NUMBER

5b. GRANT NUMBER

5c. PROGRAM ELEMENT NUMBER

6. AUTHOR(S)

George A. Luz, Edward T. Nykaza, Catherine M. Stewart, and Larry L. Pater

\section{5d. PROJECT NUMBER}

622720A896

5e. TASK NUMBER

5f. WORK UNIT NUMBER

CNN-T352

8. PERFORMING ORGANIZATION REPORT NUMBER

ERDC/CERL TR-04-26

Construction Engineering Research Laboratory (CERL)

PO Box 9005

Champaign, IL 61826-9005

\section{SPONSORING I MONITORING AGENCY NAME(S) AND ADDRESS(ES)}

U.S. Army Corps of Engineers

441 G Street N.W.

Washington, DC 20314-1000

U.S. Army Center for Health Promotion and

Preventive Medicine

5158 Blackhawk Road

Aberdeen Proving Ground, MD 21010-5402
10. SPONSOR/MONITOR'S ACRONYM(S)

CERD-ZA

11. SPONSOR/MONITOR'S REPORT NUMBER(S)

\section{DISTRIBUTION I AVAILABILITY STATEMENT}

Approved for public release; distribution is unlimited.

\section{SUPPLEMENTARY NOTES}

Copies are available from the National Technical Information Service, 5285 Port Royal Road, Springfield, VA 22161.

\section{ABSTRACT}

One of the most common sources of noise complaints around Army and Marine firing ranges is nighttime gunfire. Testing and training during the hours of darkness is absolutely essential to combat readiness. However, sound travels farther at night, and people are particularly sensitive to noise when they are trying to sleep. Currently, installation commanders are without a procedure to determine whether a particular operation is going to disturb sleep. The purpose of this research is to develop such a procedure.

The primary objective was to establish whether a commercially available instrument for measuring sleep disturbance is suitable for measuring awakening among subjects exposed to the sounds of heavy weapons. The secondary objective was to determine if there is a time when people are less sensitive to noises so that a range operator could reduce annoyance through systematic scheduling of night fire.

In general, the decibel level had an effect on the response. The higher peak decibel level was more likely to wake someone. Day of the study did not affect the response. Time was observed in some analyses to have a slight effect on waking. The feasibility of conducting a sleep disturbance study was established.

\section{SUBJECT TERMS}

noise, military training, blast noise, sleep, nighttime

\section{SECURITY CLASSIFICATION OF:}

\section{a. REPORT}

Unclassified

\section{b. ABSTRACT}

Unclassified

\section{c. THIS PAGE}

Unclassified
17. LIMITATION OF ABSTRACT

SAR
18. NUMBER OF PAGES

35

\begin{tabular}{l} 
19a. NAME OF RESPONSIBLE PERSON \\
Larry L. Pater \\
$\begin{array}{l}\text { 19b. TELEPHONE NUMBER (in- } \\
\text { clude area code) } \\
\text { (217) } 352-6511 \text {, ext } 7253\end{array}$ \\
\hline
\end{tabular}

Standard Form 298 (Rev. 8-98)

Prescribed by ANSI Std. 239.18 